\title{
E AGORA MARIA?
}

\section{Raianny Oliveira da Silva ${ }^{1}$ Deline Maria Fonseca Assunção²}

\begin{abstract}
RESUMO: Este artigo têm como objetivos analisar as intertextualidades e/ou interdiscursividades encontradas no texto literário Drumundana, de Alice Ruiz, bem como identificar quais os tipos de intertextualidade, os discursos e as relações intertextuais e relações interdiscursivas presentes nele. Para fundamentar nossa pesquisa, adotamos a Análise do Discurso de vertente francesa, essa que procura entender não só a palavra, mas também o contexto social, o espaço em que ocorre o discurso e seus efeitos de sentidos, nos permitindo ser capazes de uma relação mais elucidativa e profunda com a linguagem. Trabalhamos, nesse sentido, com os estudos de Maingueneau (1997; 2005); Orlandi (2005); Cardoso (2005); Costa (2001) e Bakhtin (2000). Tendo em vista os objetivos, nossas hipóteses levantadas foram confirmadas, além da descoberta de outro discurso tal como: o litero-musical. Para as relações intertextuais e relações interdiscursivas constatamos e confirmamos as relações de co-presença, subversão e captação.
\end{abstract}

PALAVRAS-CHAVE: Análise do Discurso. Discurso. Relações Intertextuais. Relações Interdiscursivas. Texto Literário.

\section{INTRODUÇÃO}

A Análise do Discurso francesa (doravante $A D$ ), teoria na qual fundamentamos esta pesquisa, analisa as construções ideológicas presentes em um texto, produto das atividades discursivas ou discurso, prática social de produção de textos e procura entender não só a palavra, mas também o contexto social, o espaço em que ocorre o discurso e seus efeitos de sentidos, nos permitindo ser capazes de uma relação mais elucidativa e profunda com a linguagem.

Trabalhamos, neste artigo, com os estudos de Maingueneau (1997; 2005); Orlandi (2005); Cardoso (2005); Costa (2001) e Bakhtin (2000), com o objetivo geral de analisar as intertextualidades e/ou interdiscursividades, encontradas no texto literário Drumundana, de Alice Ruiz, bem como identificar quais os tipos de intertextualidade, os discursos e as relações intertextuais e relações interdiscursivas presentes nele.

Nossa opção pela análise desse texto literário deveu-se pela intensa e transformadora influência de Carlos Drummond de Andrade sobre Alice Ruiz, o

\footnotetext{
${ }^{1}$ Graduação em Letras na Universidade Estadual do Maranhão - UEMA. E-mail: raianny03@hotmail.com

2 Mestre em Linguística (UFC) e doutora em Linguística (UFRJ). Professora Adjunto do

Departamento de Letras da UEMA/Campus Caxias. E-mail: delinemfa@hotmail.com
} 
que resultou em seu amor pela poesia. Alice nasceu em Curitiba, PR, em 22 de janeiro de 1946. É poeta (e não poetiza), como ela gosta de se denominar, compositora, tradutora e roteirista. Atualmente, destaca-se entre os poetas brasileiros contemporâneos. Publicou sua primeira obra Navalhanaliga, em 1980.

\section{PRESSUPOSTOS TEÓRICOS DA ANÁLISE DO DISCURSO}

Os processos de intertextualidade e interdiscursividade são estabelecidos quando ocorrem relações entre textos e entre discursos, respectivamente. $\mathrm{Ou}$ seja, eles se estabelecem quando, ao produzirmos textos ou discorrermos sobre algo, recorremos ao que já foi dito, como, por exemplo, composições que citam trechos de poemas e outras canções, filmes que retomam filmes, poesias que remetem a outras poesias, textos que dialogam com quadros, propagandas que se utilizam do discurso artístico, entre outros.

Orlandi (2005, p. 69) afirma que o texto "é o vestígio mais importante da materialidade do discurso, funcionando como unidade de análise, que se estabelece pela historicidade, como fonte de sentido em relação à situação", ou em relação à língua e à história. Com isso, podemos afirmar, então, que o texto, sendo a materialidade do discurso, não é homogêneo, mas caracteriza-se por distintas posições.

Maingueneau (2005, p. 57), a respeito de texto, expõe que:

Tende-se a falar de 'texto' quando se trata de produções verbais orais ou escritas, estruturadas de forma a perdurarem, a se repetirem, a circularem longe de seu contexto original. Por isso, no uso corrente, falase, de preferência, de 'textos literários', 'textos jurídicos', evitando-se chamar de 'texto' uma conversa.

Os textos mantêm relações com outros textos, por isso dizemos que o texto é um intertexto, ou seja, outros textos estão presentes em um único. Cardoso (2005, p. 61) afirma que "todo texto é um intertexto, no sentido em que outros textos estão presentes nele, em níveis variados, podendo ser conhecidos ou não".

Observa-se em Maingueneau (2005), que intertexto é o conjunto dos fragmentos citados num determinado corpus, ou seja, são vários textos em 
outros. É importante ressaltar, ainda, que essa forma de inclusão de um texto em outro varia de época para época.

Essa inclusão de um texto em outro, tangencia aquilo que entendemos por intertextualidade, que, segundo Cardoso (2005), pode ser concebida como a relação de um texto com outro previamente existente, efetivamente produzido. Isto significa dizer que todo texto, por ser produto das atividades discursivas, se relacionam com outros textos.

Os processos de intertextualidade classificam-se em intertextualidade explícita e implícita. A primeira ocorre quando a fonte citada encontra-se marcada no texto (resumos, citações de referências); a segunda, quando o interlocutor recupera a fonte na memória para a construção do sentido do texto, como é o caso das alusões e das paródias. A intertextualidade não pode ser entendida como uma simples adição de texto em um outro, mas como um texto que, de certa forma, foi modificado e incorporado em outros textos, em outra época, em outro contexto, com vistas a determinados objetivos, afinal, um discurso dito hoje, não se apresenta da mesma forma em que foi dito no passado. Os discursos, nesse sentido, perpassam pelo tempo e pela história.

Segundo Cardoso (2005, p. 21), a linguagem enquanto discurso "é, pois um lugar de investimentos sociais, históricos, ideológicos, psíquicos, por meio de sujeitos interagindo em situações concretas". O discurso revela duas faces constitutivas: uma entidade formal representada pelo sistema (língua) e a outra diz respeito à fala, essa que contempla o exercício da subjetividade atendendo às necessidades sociais. A língua, enquanto forma, apresenta uma estrutura e, ao funcionar esta língua, concretiza-se o discurso. Assim, para a $A D$, estudar o discurso significa considerar tanto o sujeito como o contexto sócio-histórico em que está inserido.

Para Maingueneau (2005, p. 15), o discurso é "uma dispersão de textos cujo modo de inscrição histórica permite definir como um espaço de regularidades enunciativas". Conforme o autor, o discurso não opera sobre a realidade das coisas, mas sobre outros discursos. O sujeito é um espaço atravessado por discursos e a língua um processo semântico e histórico. Brandão (1991) teoriza discurso como sendo toda atividade comunicativa entre interlocutores; atividade produtora de sentidos que se dá na interação entre falantes. 
Por fim, para melhor fundamentar nossa pesquisa, consideramos relevante conceituar, também, o interdiscurso, que, para Maingueneau (1997), é um processo de reconfiguração incessante, no qual uma formação discursiva é levada a incorporar elementos pré-construídos, produzidos fora dela.

Foucault (1969), citado por Mussalim (2001, p. 119), define Formação Discursiva (FD) como:

Um conjunto de regras anônimas, históricas, sempre determinadas no tempo e no espaço que definiram em uma época dada, e para uma área social, econômica, geográfica ou linguística dada, as condições de exercício da função enunciativa.

Resumidamente, toda FD é definida com base em seus interdiscursos, pois não deve ser concebida como um bloco composto que se oporia a outro, mas como uma realidade heterogênea por si mesma.

De acordo com Orlandi (2005), o interdiscurso disponibiliza dizeres que afetam o modo como o sujeito significa em uma dada situação discursiva. Isso significa afirmar que "o dizer não é uma propriedade particular. As palavras não são só nossas. Elas significam pela história e pela língua" (ORLANDI, 2005, p. 31). Chamamos de interdiscursividade a relação existente entre os discursos, estando eles dentro ou fora do mesmo contexto ou época; é a relação de um discurso com o Outro.

\subsection{Relações intertextuais e relações interdiscursivas}

Definindo a intertextualidade como o diálogo entre textos e a interdiscursividade como diálogo entre discursos, temos as relações intertextuais e as relações interdiscursivas.

Sabemos que todos os textos e todos os discursos são permeados, habitados pelo Outro, mas nem sempre é fácil estabelecer a fronteira da intertextualidade ou da interdiscursividade, pois não sabemos a partir de que momento temos os sinais evidentes de que num determinado texto há presença de outro texto ou de outro discurso. Para isso, há caminhos explícitos e implícitos, este último, torna a identificação mais demorada e difícil, principalmente quando a 
presença do outro no texto é camuflada pelo escritor. Nessa circunstância, é necessário considerar a nossa memória discursiva, que necessita de conhecimento prévio, conhecimento partilhado, contexto etc., para a identificação desse processo.

Entretanto, para abrandar essa dificuldade, podemos recorrer a uma sistematização da tipologia das relações intertextuais e das relações interdiscursivas. Lançando mão dessas tipologias, poderemos verificar, com maior precisão, qual, dentre os tipos de relações apresentadas abaixo, pode estar presente no texto, tanto no oral quanto no escrito.

Conforme Piégay-Gros (1996 apud ASSUNÇÃO, 2004, p. 35), as relações intertextuais distinguem-se em dois tipos: relações de co-presença entre dois ou mais textos e relações de derivação de um ou de vários textos a partir de um texto-matriz. Estão em relação de co-presença a citação e a referência (ambas explícitas), a alusão e o plágio (ambas implícitas);

A citação é uma das melhores formas de inserção de um texto em outro. A citação pode desempenhar várias funções em um texto, como por exemplo, o ornamento e a autoridade;

$A$ referência, como a citação, remete o leitor a um outro texto sem convocar as palavras deste. Podem, então, ser evocados personagens, títulos, lugares, épocas, pertencentes a outros textos;

O plágio é um tipo de citação não marcada, em que um texto apresenta passagens de outro texto sem indicar que isto foi feito. Está associado à regulação jurídica, na qual oferece punição para o plagiador.

A alusão não explicita a retomada intertextual, como o plágio, e, do mesmo modo que a referência, não convoca as palavras do outro. Para que a alusão tenha efeito, é necessário que o leitor conheça e recupere o texto aludido por meio de poucos indícios colocados à disposição pelo autor, tais como; palavras, entonações, estilos, formas textuais etc.

Nas relações de derivação estão o pastiche, o travestimento burlesco e a paródia.

O pastiche imita o estilo de um texto, ou seja, ele não age sobre um texto específico, mas sobre um "jeito textual" que um mesmo autor cultua. 
A paródia modifica o assunto ou o conteúdo de um texto conservando o seu estilo ou sua estrutura. Maingueneau (1997) entende que a paródia está relacionada à depreciação do texto-matriz, em decorrência disso, prefere falar da imitação. Segundo o autor, a imitação pode assumir dois valores que se opõem: a captação e a subversão. Na primeira, um texto imita outro seguindo a mesma direção com o intuito de beneficiar-se da autoridade do enunciado do outro. É o caso da estilização, que imita o estilo do autor, independentemente da obra. $\mathrm{Na}$ segunda, um texto imita outro, visando desqualificar este movimento de imitação, caso da paródia.

O travestimento burlesco aproveita o conteúdo, mas modifica completamente a estrutura ou o estilo do texto anterior. É interessante ressaltar que o travestimento burlesco é utilizado para ironizar o texto derivante, atualizar textos arcaicos e também para simplificar textos eruditos.

Tendo por base o fato de o travestimento burlesco estar excessivamente direcionado ao discurso literário e que a paródia é sempre tomada com um sentido depreciativo, Costa (2001, p. 46) faz uma modificação geral nas relações de derivação de Piégay-Gros e acrescenta, seguindo as sugestões de Maingueneau (1997), a categoria imitação captativa e subversiva ao esquema das relações intertextuais ficando constituído da seguinte forma:

\begin{tabular}{|c|c|c|}
\hline \multirow{4}{*}{$\begin{array}{c}\text { Relações } \\
\text { Intertextuais }\end{array}$} & $\begin{array}{c}\text { Relações de co- } \\
\text { presença }\end{array}$ & Citação \\
\cline { 3 - 3 } & $\begin{array}{c}\text { Relações de } \\
\text { derivação e } \\
\text { imitação }\end{array}$ & $\begin{array}{c}\text { Captativa - Pastiche } \\
\text { estilização }\end{array}$ \\
\cline { 3 - 3 } & & Subversiva - Paródia \\
\cline { 3 - 3 } & &
\end{tabular}

Com isso, considerando a classificação dos elementos intertextuais relacionados por Piegay-Grós, apresentados e reformulados, Costa (2001, p. 48) diz que as relações interdiscursivas "consistem nas relações da enunciação com o interdiscurso, isto é, com o suposto exterior discursivo". Diante disso, o autor apresenta uma outra sistematização, formada a partir do esquema das 
relações intertextuais exposto antes, em que, nas relações de co-presença, estão a referência e a alusão e, nas relações de imitação, estão a imitação captativa e a imitação subversiva.

\begin{tabular}{|c|c|c|l|}
\hline \multirow{4}{*}{$\begin{array}{c}\text { Relações } \\
\text { Interdiscursivas }\end{array}$} & $\begin{array}{c}\text { Relações de co- } \\
\text { presença }\end{array}$ & Referência & $\begin{array}{l}\text { Cenografia } \\
\text { Validada }\end{array}$ \\
\cline { 2 - 3 } & $\begin{array}{c}\text { Relações de } \\
\text { Imitação }\end{array}$ & Alusão & $\begin{array}{l}\text { Ethos } \\
\text { Palavras }\end{array}$ \\
\cline { 2 - 3 } & Captativa & $\begin{array}{l}\text { Códigos de } \\
\text { linguagem } \\
\text { Gêneros etc. }\end{array}$ \\
\hline
\end{tabular}

A referência interdiscursiva acontece "quando um texto pertencente a uma formação discursiva comenta, descreve, representa ou refere-se de alguma forma a outra formação discursiva ou ao interdiscurso" (COSTA, 2001, p. 50).

A alusão interdiscursiva, geralmente se dá através do ethos e utiliza recursos como um jogo com as palavras, como a implicitação, o disfarce, entre outros. Dispensa, principalmente, a representação de trechos alheios (citação intertextual) e a menção de personagens, cenários e autores (referência discursiva);

$\mathrm{Na}$ captação interdiscursiva um texto pode mimetizar o ethos de outros discursos para legitimar seu discurso.

Por fim, na subversão interdiscursiva os textos podem incorporar parodicamente ethos, cenários validados, códigos de linguagem etc. de outras formações discursivas para subvertê-los, legitimando-se por oposição.

É considerável ressaltar que esses conceitos são proveitosos, no entanto, nem todos os tipos dessas relações, tanto intertextuais quanto interdiscursivas, foram encontrados no texto analisado.

\section{ANÁLISE DA INTERTEXTUALIDADE E/OU INTERDISCURSIVIDADE NO TEXTO LITERÁRIO DRUMUNDANA, DE ALICE RUIZ.}


Para a realização de nossas análises, é importante levar em consideração que a intertextualidade e a interdiscursividade se diferenciam, porém podem uma conter a outra, ou seja, uma intertextualidade sempre será uma interdiscursividade, mas o inverso não acontece. Como vimos antes, de acordo com Costa (2001), as relações intertextuais se manifestam sob relações de copresença: citação; referência; alusão e plágio, de derivação captativa: pastiche e estilização e de derivação subversiva: paródia; as relações interdiscursivas são manifestadas através das referências e alusões interdiscursivas, que são relações de co-presença e, também, através das relações de imitação: captação e a subversão interdiscursivas. Consideramos neste artigo, principalmente, as relações intertextuais de paródia e citação, e como relações interdiscursivas, a captação e a subversão interdiscursiva.

\subsection{Drumundana, Alice Ruiz.}

DRUMUNDANA

e agora Maria?

o amor acabou

a filha casou

o filho mudou

teu homem foi pra vida

que tudo cria

a fantasia

que você sonhou

apagou

à luz do dia

e agora maria?

vai com as outras

vai viver

com a hipocondria. (RUIZ, 1980, p. 60) 
A pluralidade de Alice Ruiz, somada à sua vontade de dialogar com outras obras e autores de diferentes épocas, passadas ou presentes, inspirou-a na leitura de muitos artistas atrelados à música, à poesia, à literatura em geral.

Em Drumundana, na qual o discurso intertextual da paródia deu um diferencial ao colocar um eu feminino, com problemas tão graves quanto os de "José", poesia escrita por Drummond, na década de 40, Ruiz traz, no título de seu poema, a ideologia da mulher que vive para a família e, quando cada um toma seu rumo, sente-se ameaçada, perdida, nada resta para ela a não ser consolar-se com medicamentos.

Há também, neste título, a palavra "mundana", que assume a ideia associada a algo sem valor, sem dignidade, socialmente desprezível. Este aspecto é de maior importância e assume um caráter irônico, uma vez que a que não tem valor, como se vê no poema, é Maria, nome comum, como José, que pode representar qualquer mulher que, a certo momento da vida, vê desmoronar os pilares que a sustentavam.

Abaixo, transcrevemos o poema de Drummond, o qual é a fonte, o arquétipo do poema de Ruiz.

\section{JOSÉ}

Carlos Drummond de Andrade

E agora, José?

A festa acabou,

a luz apagou,

o povo sumiu,

a noite esfriou,

e agora, José?

e agora, você?

você que é sem nome,

que zomba dos outros,

você que faz versos,

que ama, protesta?

e agora, José? (...) (ANDRADE, 2007, p. 106) 
No momento em que temos Drumundana, a primeira questão a ser pensada é a de que Alice Ruiz recuperou o nome do poeta Drummond e, ao mesmo tempo que temos um diálogo com o $E$ agora, José, temos, também, uma outra conversa, que agora não está mais no José, agora está na Maria; "E agora, Maria?". O poema de Alice Ruiz dialoga com o de Drummond não só o parodiando, mas também numa individualidade que comparece na percepção do destino trágico de alguém que não tem nobreza. $O$ destino está em ser condenada, depois de tantas perdas, a ser uma Maria "vai com as outras", a somatizar as dores, a não poder ou não ter forças e condições de forjar o destino, de ser ela mesma, mas igual às outras.

Um outro aspecto a ser destacado diz respeito ao tamanho do poema de Alice Ruiz, que é bastante conciso e construído com uma pontuação por demais livre. Se, por um lado, o poema de Drummond ostenta um eu lírico que apresenta marcas de uma certa nobreza ("sua bíblia", "sua lavra de ouro", "seu terno de vidro" - "se você tocasse a valsa vienense", "você que faz versos"), por outro, o de Ruiz traz uma história de fracasso nascido da condição feminina e seus condicionamentos. O eu lírico não tem emprego, vive de ausências e perdas, da falta de sonhos e fantasias, como podemos perceber nos seguintes versos ("a fantasia", "que você sonhou", ou "o filho mudou", "teu homem foi pra vida"). Parece ser alguém que apostou ou foi levado a apostar "suas fichas" num modelo de família em que cabe à mulher dedicar-se à criação dos filhos e cuidar da casa e do marido. Mas, quando eles se vão, quando o amor acaba, surge o vazio profundo, a falta de perspectivas. Maria pode ser lida, portanto, como uma espécie de representação da condição de muitas mulheres.

Nessa poética feminista, há também uma crítica direta com a intenção explícita de apontar os paradoxos, numa inversão desestabilizante do pensamento. Alice se autodenomina poeta, provavelmente, por sua formação feminista dos anos 1970, na qual se via muito mais a luta pela igualdade entre os sexos do que a valorização das diferenças entre eles, como é o caso do feminismo nos dias de hoje.

E, se "José", de Carlos Drummond de Andrade, era um homem com conflitos dentro de uma existência masculina já explorada e vivida (não há mais 
caminhos), a Maria, na poesia Drumundana, de Ruiz, é uma mulher limitada pela existência dentro de um "padrão do feminino": ela viveu a vida que se esperava de uma mulher, para o marido e para os filhos, sempre na esfera privada. No olhar da poeta, uma vida resumida, fechada, sem sentido, uma não-vida. Se José insiste em caminhar e ir em frente apesar das limitações, Maria só pode esperar a morte, porque aprendeu a morte em vida.

A não-vida de "Maria" é mostrada através de uma crítica ao olhar machista de que a mulher nasceu para casar e ter filhos, impedindo-a de procurar outros caminhos.

Percebemos, com isso, o discurso feminista de Alice Ruiz, que mostra o padrão feminino da mulher do lar, o que, de certo modo, reflete uma crítica a essa visão arcaica e tradicionalista com relação ao sexo feminino, fato esse que nos faz pensar sobre o motivo pelo qual a autora foi inspirada e motivada a usar 0 texto de Drummond como intertexto. A priori, temos um "José", que se questiona da realidade com mais vigor; que tem a preocupação com problemas do homem na tentativa de explorar o estar no mundo; a preocupação com os sonhos, os desejos: [...] "Está sem mulher,.../ não veio a utopia.../...e agora, José?" [...]. (ANDRADE, 2007, p. 106).

E uma "Maria", que também se questiona sobre o estar no mundo ao indagar "E agora, Maria?", mas que apaga suas fantasias, seus sonhos e espera somente pelo fim que aprendeu em vida (morte).

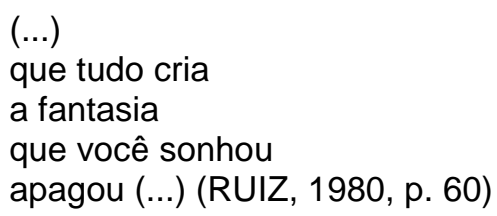

Diante desse diálogo que o texto Drumundana estabelece com o de Drummond, notamos que um texto nunca é isolado, isso nos remete ao dialogismo bakhtiniano, que é exatamente a ideia de recuperação de algo que já passou ("E agora, José?") e, também, de algo que podemos projetar para o futuro (“E agora, Maria?"). Nessa perspectiva, percebemos que, ao dialogar com o texto do outro, da alteridade e em questão específica, com o de Drummond, o texto de Ruiz, estabelece um outro sentido, agora, feminista, com problemas diferentes 
dos de "José", mas tão graves quanto os dele. Encontramos, assim, a partir desse novo diálogo, uma mudança de vocabulário, em que antes ainda existia esperanças, insistindo em caminhar e ir em frente, sem desistir, "José é duro":

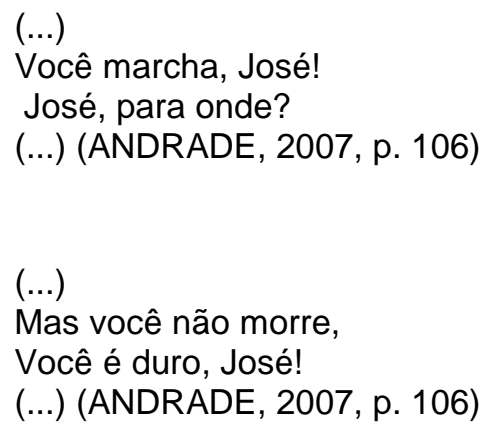

E agora se mostrando mais pessimista, tanto com relação ao eu quanto ao mundo numa consciência da fragilidade do eu-feminista, que vai viver, mas viver com a hipocondria, esperando a morte que aprendeu em vida:

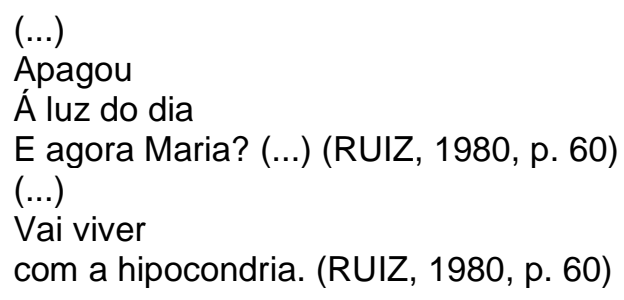

É importante salientar que esses diálogos, em que precisamos voltar e nos perguntar quem é o interlocutor do autor, nos remetem a ideia de que, se não temos na memória quem foi o "José" e quem era o Drummond, o texto de Ruiz fará um sentido muito restrito. Mas, se temos essas informações, estabelecemos um diálogo grande, não só com o momento de hoje, mas também, com o passado, no qual podemos, diante disso, nos perguntar sobre: "E agora, Maria?", as Marias de hoje, e "E agora, José", o José do passado, que se torna vivo dentro do poema Drumundana, de Alice Ruiz, estabelecendo uma relação intertextual de derivação subversiva - paródia -, e uma relação interdiscursiva de subversão interdiscursiva, numa relação de diálogo entre os discursos literários de Drummond e de Alice Ruiz. 
Outros motivos pelos quais podemos imaginar que levaram Ruiz a manter essa relação intertextual com o poema de Drummond, como dissemos antes, se justifica pela intensa e transformadora influência de Carlos Drummond de Andrade sobre a autora, o que resultou em seu amor pela poesia e a informação de que, além de Drumundana, Alice Ruiz tem outros poemas que dialogam com os de Drummond, como no caso do poema Caminho de pedra, que faz alusão ao poema No meio do caminho, do mesmo poeta. Diante dessas informações, notamos que, de fato, as nossas falas estão sempre constituídas do eu e do outro, validando estruturas, contrapondo e ritmando palavras.

Partindo dessa compreensão, nos dispomos a analisar uma outra intertextualidade e interdiscursividade, essa, dentro do campo musical. Os versos "e agora Maria?" "vai com as outras", citado por Ruiz, nos remete a letra de Vinicius de Moraes para a canção "Maria vai com as outras".

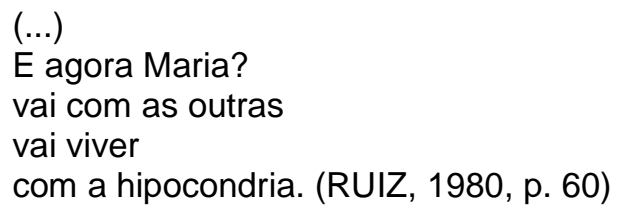

Abaixo, transcrevemos a música de Vinicius de Moraes, cujo título, possivelmente, é a fonte usada por Ruiz, para compor seus versos:

Maria Vai Com As Outras

Vinicius de Moraes

Maria era uma boa moça

Prá turma lá do Gantois

Era Maria vai com as outras

Maria de coser, Maria de casar

Porém o que ninguém sabia

É que tinha um particular

Além de coser, além de rezar

Também era Maria de pecar 
Tumba é caboclo

Tumba lá e cá

Tumba é guerreiro. (MORAES, 1971).

"Maria vai com as outras" era uma expressão muito usada no passado e ainda nos dias de hoje; um modo informal e tradicionalista de dizer que alguém é influenciável, de personalidade fraca, desprovido de opinião própria. O que transmitia a ideia machista de que não existe expressão similar para o masculino, ou seja, quando uma mulher pensava de forma diferente da "conveniente para seu gênero" (ou dos estereótipos sobre), era chamada de Maria vai com as outras, deixando sempre implícita na frase a incapacidade das mulheres de tomarem decisões sozinhas ou de pensarem diferente.

Esse diálogo com a música de Vinicius caracteriza uma relação intertextual de co-presença, ao citar o verso da canção de Moraes como intertexto, e interdiscursiva, pois o discurso de Alice Ruiz está no campo literário e o de Vinicius de Moraes no campo musical (ou lítero-musical), essa relação interdiscursiva se caracteriza pela captação interdiscursiva. São, portanto, gêneros diferentes dialogando sob a ótica dos discursos feminista e machista. É considerável frisar que a inserção do verso "Maria vai com as outras", no poema de Ruiz, atribui ao texto da poeta outro efeito de sentido, pois a "Maria", de Alice Ruiz, sem vida e esperança, "vai com as outras", enquanto que a "Maria", de Vinicius, se mostra menos presa a um padrão feminino pré-estabelecido, no sentido de, além de coser, casar e rezar, era também de pecar. Os dois textos mantêm, com o uso da expressão, a mesma crítica ao discurso machista, crítica essa expressa de maneira mais clara na música pelo uso da palavra "pecar" e mais conformal no poema, que mostra uma "Maria" sem perspectivas e sem esperanças, depois de uma vida voltada para o lar. É cabível destacar também, que a pontuação do verso "Maria? vai com as outras" no poema, é diferente de "Maria vai com as outras" da canção de Moraes, o que transmite a ideia de que, no poema, a própria autora se faz essa pergunta, levando em consideração que ela tinha uma vida totalmente diferente do discurso que levava (ela cuidava das crianças e da casa, enquanto o marido trabalhava), só decidiu mudar essa realidade, quando viu sua filha imitando seus afazeres domésticos e sentiu a 
necessidade de ser um outro tipo de exemplo para ela, assumindo, nesse sentido, seu discurso feminista.

Conforme Medeiros (2016), para Luís da Câmara Cascudo, historiador, antropólogo, advogado e jornalista brasileiro - a expressão tem sua origem e se refere a Dona Maria I, mãe de D. João VI (avó de D. Pedro I e bisavó de D. Pedro II). Ela enlouqueceu de um dia para o outro e foi declarada incapaz de governar, sendo afastada do trono. Passou a viver recolhida e só era vista quando saía para caminhar a pé, escoltada por numerosas damas de companhia. Quando o povo via a rainha levada pelas damas nesse cortejo, costumava comentar: "Lá vai D. Maria com as outras". Atualmente, aplica-se a expressão a uma pessoa que não tem opinião e se deixa convencer com a maior facilidade.

Uma outra possível explicação para origem dessa expressão é a de João Batista Ribeiro de Andrade Fernandes, mais conhecido como João Ribeiro, jornalista, crítico literário, filólogo, historiador, pintor e tradutor brasileiro, ele acredita numa origem religiosa e bem diferente: o fato de serem mencionadas frequentemente juntas "as três Marias da Lei nova: Maria, Nossa Senhora; Maria Madalena; e Maria, irmã de Lázaro", "Maria vai com as outras, Marias". (VEJA, 2016).

Essas informações nos permitem dizer que Vinicius de Moraes poderia já ter usado essa expressão como intertexto, uma vez que ela é anterior. Dessa maneira, reiteramos diante de nossas análises que os diálogos são incessantes e que as pessoas, quando dialogam, recuperam conversas e fatos anteriores, atribuindo a esses diálogos novos sentidos, ideias, numa outra época e com determinados objetivos.

\section{CONCLUSÃO}

Conforme os pressupostos teóricos da AD, objetivamos analisar a intertextualidade e a interdiscursividade presentes no texto literário Drumundana, de Alice Ruiz. O presente estudo foi motivado pela curiosidade de verificar esses processos discursivos em texto literário, já que é através deles que o leitor pode fazer interpretações mais elucidativas, mobilizando o máximo de conhecimento sobre o que está ouvindo, vendo ou lendo. 
Após nossas análises, constatamos os processos da intertextualidade e da interdiscursividade entre os textos e discursos de caráter literário, lítero-musical, feminista e machista, comprovando, com isso, o amplo repertório cultural da escritora em estudo. Para marcar as relações intertextuais, a autora usou, predominantemente, a citação (relação de co-presença); a paródia (relação de derivação e imitação subversiva). Para as relações interdiscursivas, a subversão e a captação.

Concluímos este trabalho ressaltando sua relevância em incentivar o olhar crítico e reflexivo dos leitores sobre o que ouvem, veem ou leem, essas características propiciam diferentes posicionamentos e questionamentos acerca dos discursos veiculados nos diferentes meios de comunicação tais como: jornais, quadros, revistas, livros, rádio, televisão, internet.

\section{AND NOW MARIA?}

ABSTRACT:This article has as objective to analyze the intertextuality and/or interdiscursivities found in literary text Drumundana, Alice Ruiz and identifies what types of intertextuality, the speeches and the intertextual relations and interdiscursive relations present in it. To support our research, we adopted the analysis of the French side of speech, one that seeks to understand not only the word but also the social context, the space in which occurs the speech and its effects senses, allowing us to be able to a relationship more informative and deep with language. We work in this direction, with studies Maingueneau (1997; 2005); Orlandi (2005); Cardoso (2005); Costa (2001) and Bakhtin (2000). In view of the objectives, our hypotheses were confirmed, in addition to the discovery of another speech such as the literary-musical. For the intertextual relations and relations, interdiscursive found and confirmed the relationship of co-presence, subversion, and funding.

KEYWORDS: Discourse Analysis. Speech. Intertextual Relationships. Interdiscursive Relationships. Literary Text.

\section{REFERÊNCIAS}

ANDRADE, Carlos Drummond de. Poesia completa: conforme as disposições do autor. Rio de Janeiro: Nova Fronteira, 2007.

ASSUNÇÃO, Deline Maria Fonseca, Organização discursiva da festa do Bumba-meu-boi do Maranhão. Fortaleza, 2004, 163 p. Dissertação (Mestrado em Linguística). Programa de Pós-graduação em Linguística, Universidade Federal do Ceará.

BAKHTIN, Mikhail Mikhailovitch. Estética da criação verbal. 3. ed. São Paulo: Martins Fontes, 2000, pp. 279-326. 
BRANDÃO, Helena H. Nagamine. Introdução à análise do discurso. Campinas, SP: Ed. UNICAMP, 1991.

CARDOSO, Silva Helena Barbi. Discurso e ensino. 2. ed. Belo Horizonte: Autêntica, 2005.

COSTA, Nelson Barros da. A produção do discurso lítero-musical brasileiro. São Paulo, 2001. 486f. Tese (Doutorado em Linguística Aplicada). Programa de Pós-Graduação em Linguística Aplicada e Estudos da Linguagem, Pontificia Universidade Católica de São Paulo.

MAINGUENEAU, Dominique. Novas tendências em análise do discurso. 3. ed. Campinas-SP: Pontes, 1997.

. Análise de textos de comunicação. São Paulo: Cortez, 2005.

MEDEIROS, Rostand. Ditados populares e seus significados. São Paulo, 2016. Disponível em: <https://tokdehistoria.com.br/2013/01/16/ditados-popularese-seus-significados-segundo-cascudo/>. Acesso em: 28 de out. de 2016.

MORAES, Vinicius. Maria vai com as outras. Rio de Janeiro: Tonga Editora Musical LTDA, 1971. Disponível em: <http://www.viniciusdemoraes.com.br/pt$\mathrm{br} / \mathrm{musica} /$ cancoes/maria-vai-com-outras>. Acesso em: 10 de ago. de 2016.

MUSSALIM, Fernanda. Análise do discurso. In: MUSSALIM, Fernanda; BENTES, Anna Cristina (orgs.). Introdução à linguística: domínios e fronteiras. 2. ed. São Paulo: Cortez, 2001. v. 2.

ORLANDI, Eni Puccinelli. Análise do discurso: princípios e procedimentos. 6. ed. Campinas-SP: Pontes, 2005.

RUIZ, Alice. Navalhanaliga. Curitiba: ZAP22, 1980.

VEJA.COM. Maria vai com as outras porque é maria-vai-com-as-outras. 2016. Disponível em: <http://veja.abril.com.br/blog/sobre-palavras/consultorio/maria-vaicom-as-outras-porque-e-maria-vai-com-as-outras/>. Acesso em: 28 de out. 2016.

Data de Submissão: 24/03/17

Data de Aprovação: 06/05/17 